\title{
VARIA
}

\section{NUEVAS PINTURAS DE CESARE ARBASIA EN LA CATEDRAL DE CÓRDOBA}

\author{
M. Ángeles Jordano Barbudo ${ }^{1}$ \\ Universidad de Córdoba
}

\begin{abstract}
En la capilla de los Simancas, también del Espíritu Santo o de los Obispos, en la Mezquita-Catedral de Córdoba, se han descubierto unas pinturas murales que representan figuras de profetas atribuidas a Cesare Arbasia (1547-1614). Palabras clave: Profetas; Hernán Ruiz II; Hernán Ruiz III; Pablo de Céspedes; manierismo; pintura al fresco.
\end{abstract}

\section{NEWLY DISCOVERED PAINTINGS BY CESARE ARBASIA IN THE CATHEDRAL OF CORDOBA, SPAIN}

Mural paintings depicting three prophets have been discovered in the Simancas Chapel, also known as the Chapel of the Holy Spirit or Chapel of the Bishops, in the Mosque-Cathedral of Cordoba. These have been attributed to Cesare Arbasia. Key words: prophets; Hernán Ruiz II; Hernán Ruiz III; Pablo de Céspedes; Mannerism; fresco painting.

Cómo citar este artículo / Citation: Jordano Barbudo, M. ${ }^{a}$ Ángeles (2021) "Nuevas pinturas de Cesare Arbasia en la catedral de Córdoba”. En: Archivo Español de Arte, vol. 94, núm. 374, Madrid, pp. 163-171.

https://doi.org/10.3989/aearte.2021.10

Las pinturas que aquí se van a estudiar han aparecido en la capilla de los Simancas, que se encuentra adosada al muro este de la ampliación de Almanzor en la antigua mezquita aljama de Córdoba. En 1568 el cabildo dio el sitio para su construcción a Juan de Simancas, en aquel entonces arcediano de Córdoba ${ }^{2}$. Sus trazas se han atribuido a Hernán Ruiz II ${ }^{3}$, pero al morir en 1569, la mayor parte de la obra debió realizarla su hijo Hernán Ruiz III, sintetizando en este espacio las influencias de Riaño, Diego de Siloé, Serlio y Palladio [fig. 1] $]^{4}$.

La capilla fue edificada bajo la advocación del Espíritu Santo por Diego de Simancas (1513$1583)^{5}$, obispo de Zamora ${ }^{6}$, aunque también se conoció como capilla de los Obispos porque su

\footnotetext{
1 ajordano@uco.es / ORCID iD: https://orcid.org/0000-0002-7682-7384

2 Concesión del cabildo de Córdoba de un lugar para enterramiento a don Juan de Simancas, 4 de septiembre de 1568, Archivo Catedral de Córdoba (ACC), Actas Capitulares, t. 19, ff. 179r-v.

${ }^{3}$ Banda y Vargas, 1999: 391. Nieto Cumplido, 1991: 209-245.

${ }^{4}$ Chueca Goitia, 1953: 265. Morales, 1996. Villar Movellán, 1990: 364.

${ }_{5}^{5}$ Escritura de Fundación de la capilla de los Simancas, 13 de marzo de 1583, Archivo Capitular de Córdoba (ACC), Capellanías, legajo 7.027, ff. 64r-67r. ACC, Colección Vázquez Venegas (CVV), 035-2, f. 35r.

6 También fue obispo de Ciudad Rodrigo (nombrado en 1564) y de Badajoz (1569-1578). Su trayectoria vital y escritos en Lynn, 2013: 88-138. Desde una óptica crítica, véase Caro Baroja, 1970: 15-63. Su breve protagonismo como virrey de Nápoles en Moralejo Ortega, 2012: 141-153.
} 


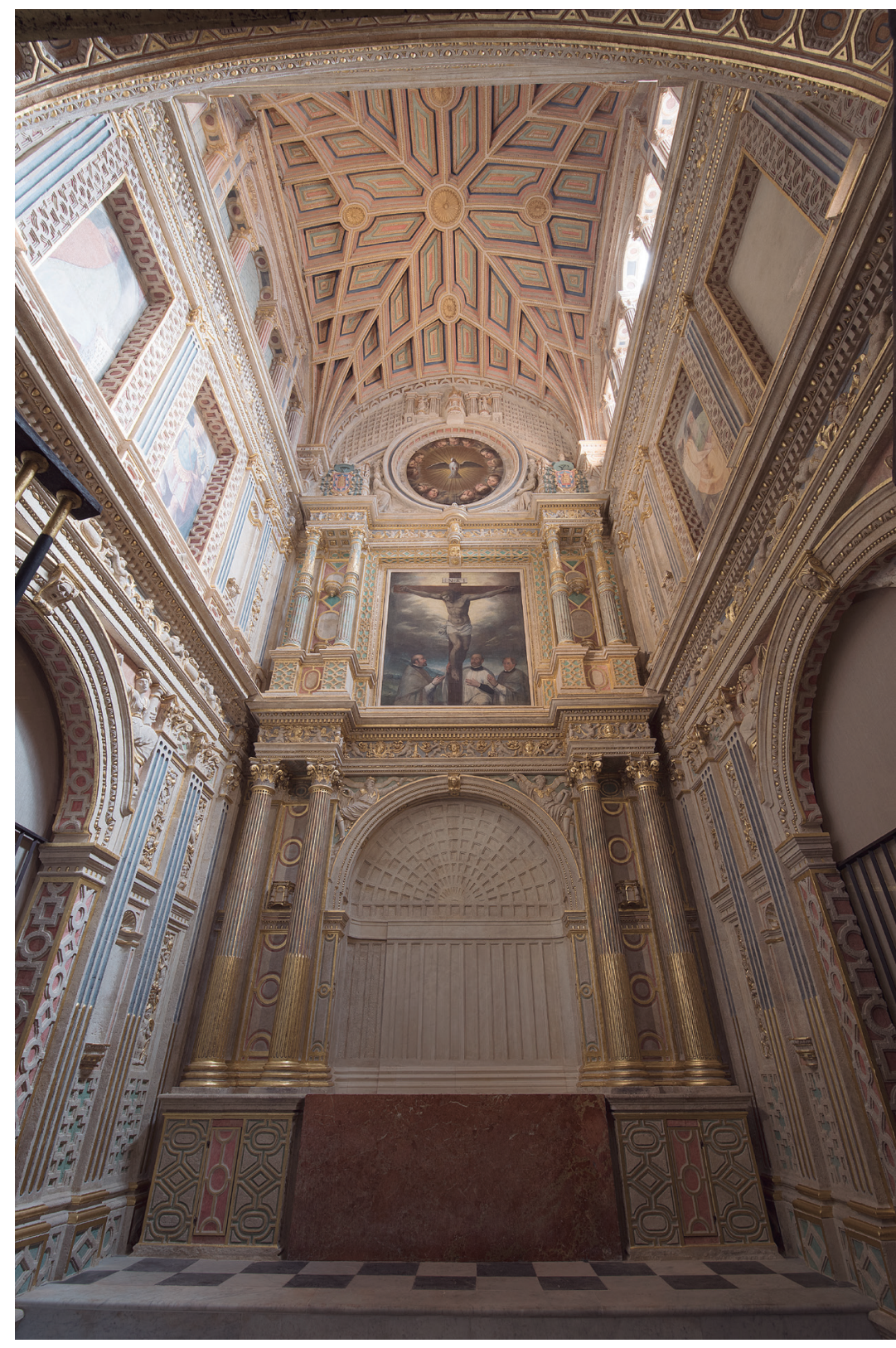

Fig. 1. Córdoba, catedral, capilla del Espíritu Santo, retablo, ca. 1568-1579.

hermano Juan fue mitrado de Cartagena de Indias (1558-1568)7 . Este debió hacerse cargo del seguimiento de las obras mientras Diego se encontraba en Roma - de 1567 a 1576- en la causa inquisitorial contra el arzobispo Carranza ${ }^{8}$. Según su autobiografía, la capilla le costó 9.000 ducados 9 .

7 Díaz Rodríguez, Antonio. "Juan de Simancas”. En: Real Academia de la Historia, Diccionario Biográfico electrónico. En: http://dbe.rah.es/biografias/121551/juan-de-simancas [20/05/2020].

${ }^{8}$ En 1571 Juan llegó a Badajoz para ocuparse durante casi cinco años de la diócesis mientras Diego estaba en Roma (Lynn, 2013: 127).

9 Simancas, 1905: 203. Murió en Zamora en 1583 (Escritura de dotación, fundación, erección y nueva creación de la capilla del Espiritu Santo por don Diego de Simancas, 13 de marzo de 1583, Archivo General Obispado de Córdoba (AGOC), Capellanías, 1137/01, leg. 211 1262, ff. 1r-12r). 


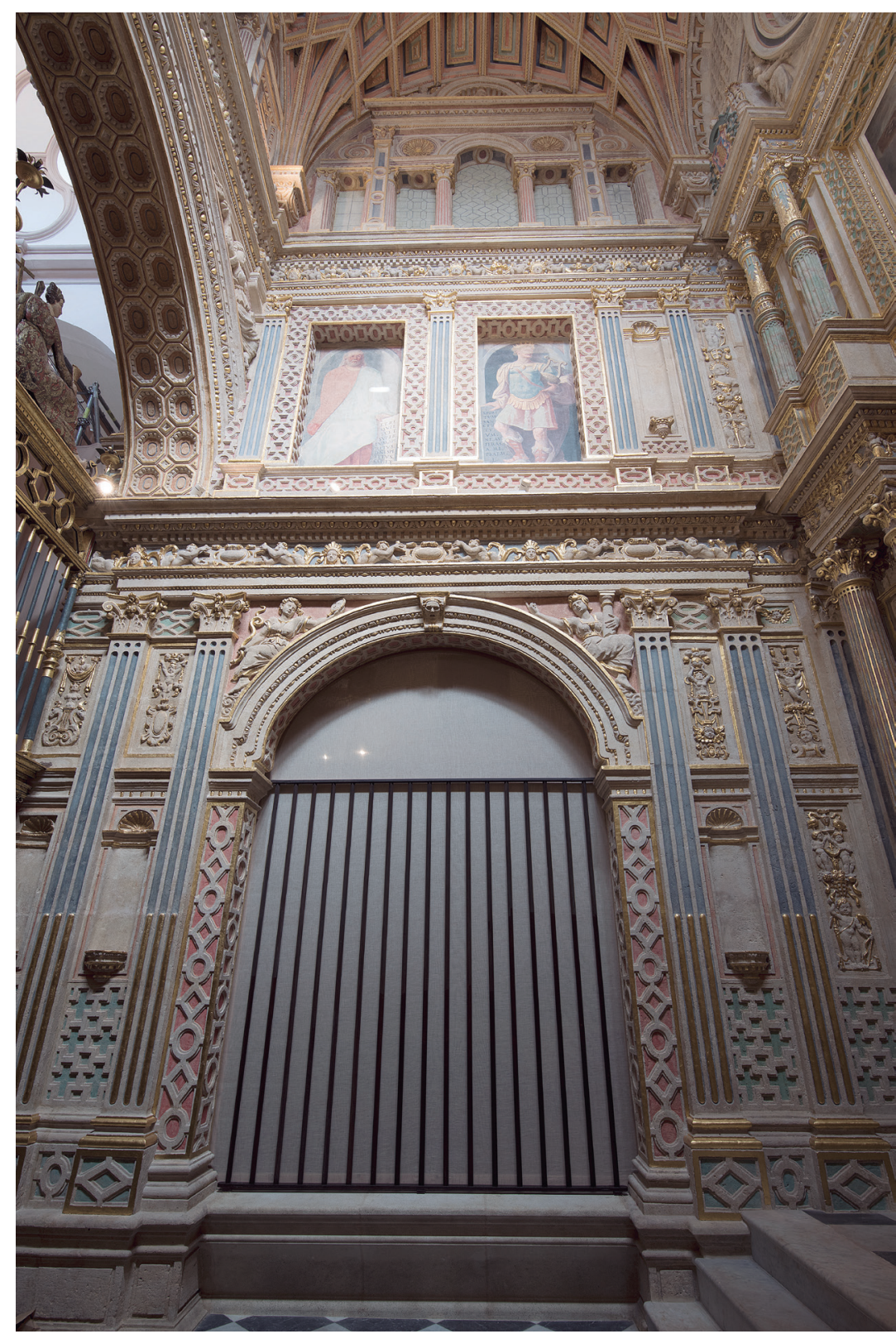

Fig. 2. Córdoba, catedral, capilla del Espíritu Santo, muro norte, con pinturas de Isaías (izqda.) y David (dcha.) en el segundo nivel.

\section{Las pinturas}

Los profetas recientemente aparecidos — cuatro en origen, aunque uno de ellos está completamente perdido- se hallan enfrentados dos a dos en los lados norte y sur, en el segundo nivel, y fueron pintados al fresco prácticamente a tamaño natural [fig. 2].

Los tres personajes conservados son David, Moisés e Isaías. Los dos primeros están más próximos al altar y el tercero se halla a continuación de David, en el muro septentrional. David, sin duda el de mayor calidad artística, aparece vestido como un soldado romano, con amplio manto, coraza, túnica corta y borceguíes [fig. 3]. Aplasta el casco de Goliat con su pie, mientras sostiene en su 


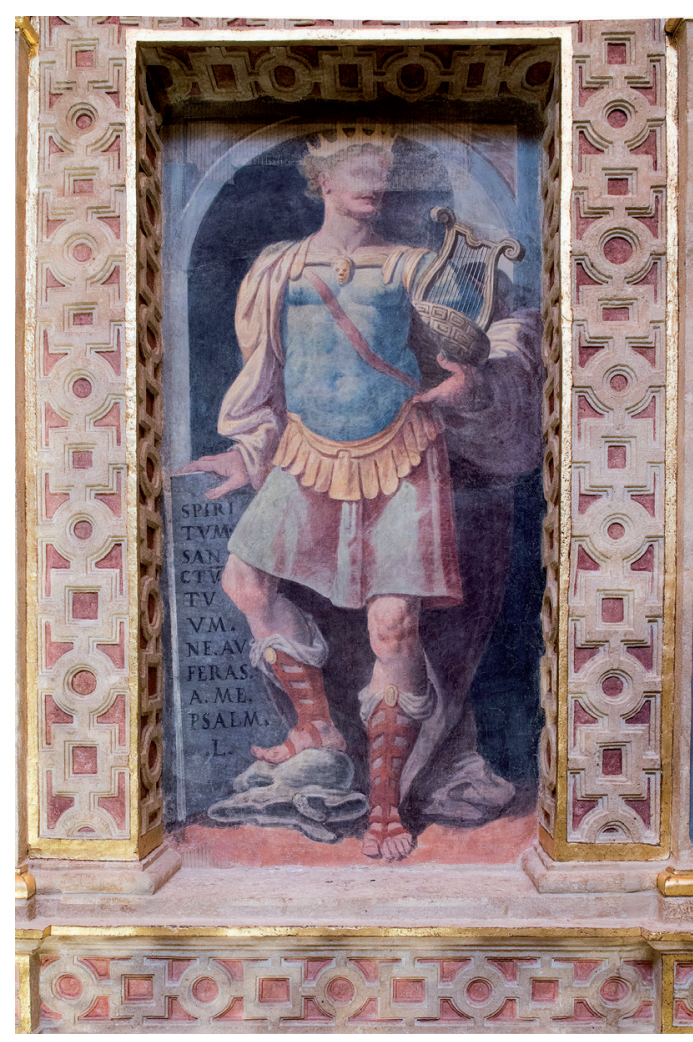

Fig. 3. Córdoba, catedral, capilla del Espíritu Santo, el profeta David.

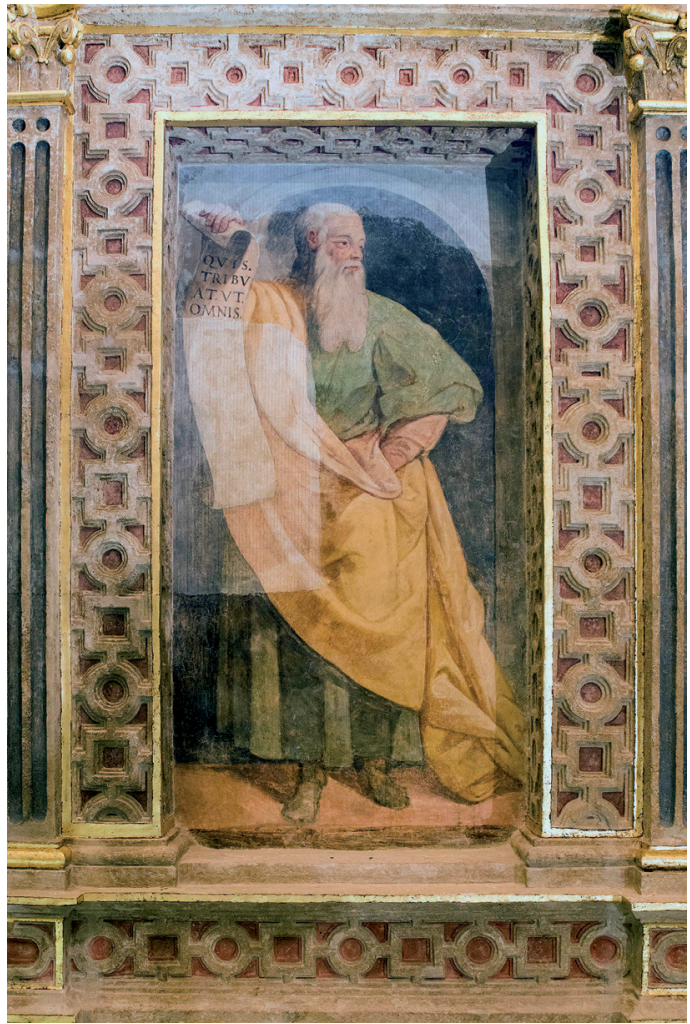

Fig. 4. Córdoba, catedral, capilla del Espíritu Santo, el profeta Moisés.

mano izquierda el arpa y apoya la opuesta sobre la lápida cuya leyenda le identifica: "Spiritum Sanctum ne auferas me. Psalm L" [No apartes de mí tu Santo Espíritu. Salmo 50] ${ }^{10}$.

Difiere de la lozana juventud del rey David el profeta Moisés, de cabello cano y larga barba blanca [fig. 4]. Despliega en su filacteria "Quis tribuat, ut omnis [...]", interrumpida al haber desaparecido el resto de la cita, que continuaría: "[...] populus prophetes" ${ }^{11}$. Las palabras parecían escogidas para los Simancas, pues animaban a convertirse en buenos predicadores, a los cuales Dios dotaría de espíritu para honrarle, darle gloria y extender su nombre en todo el mundo ${ }^{12}$.

El tercer personaje es el profeta Isaías, en el recuadro noroeste [fig. 5]. A pesar de estar en su mayoría perdido, su identificación la ha facilitado la filacteria: "Et requiescet super eum spiritus domini, spiritus sapientiae et intel[ectus]. Esaias. Cap. 11"13. El fragmento del versículo alude a dos de los siete espíritus o dones de Dios, la sabiduría y el entendimiento, que debían adornar a los Simancas al predicar.

Las formas manieristas que acusan las pinturas fueron introducidas en Córdoba desde Italia gracias al racionero de la catedral Pablo de Céspedes ${ }^{14}$, quien estuvo allí durante siete años, junto a Cesare Arbasia al que trajo consigo en $1577^{15}$ :

\footnotetext{
${ }^{10}$ Sigüenza/García/Fernández/Palomino (2014): 169.

11 Núm. 11.

12 Rodríguez, 1760: 130.

13 "Sobre él [el Mesías] reposará el espíritu de Yahvé: espíritu de sabiduría y de entendimiento. Isaías. Capítulo 11" (Isaías 11: 1-2).

14 Martínez Lara, 2018: 201-213.

15 Quílez, 1990: 66-67, nota 1. Díaz Cayeros, 2006: 11-14. Martínez, 1968: 293. Urquízar, 2001b: 91, nota 53. Pacheco/Piñero/Reyes (1985): 102.
} 


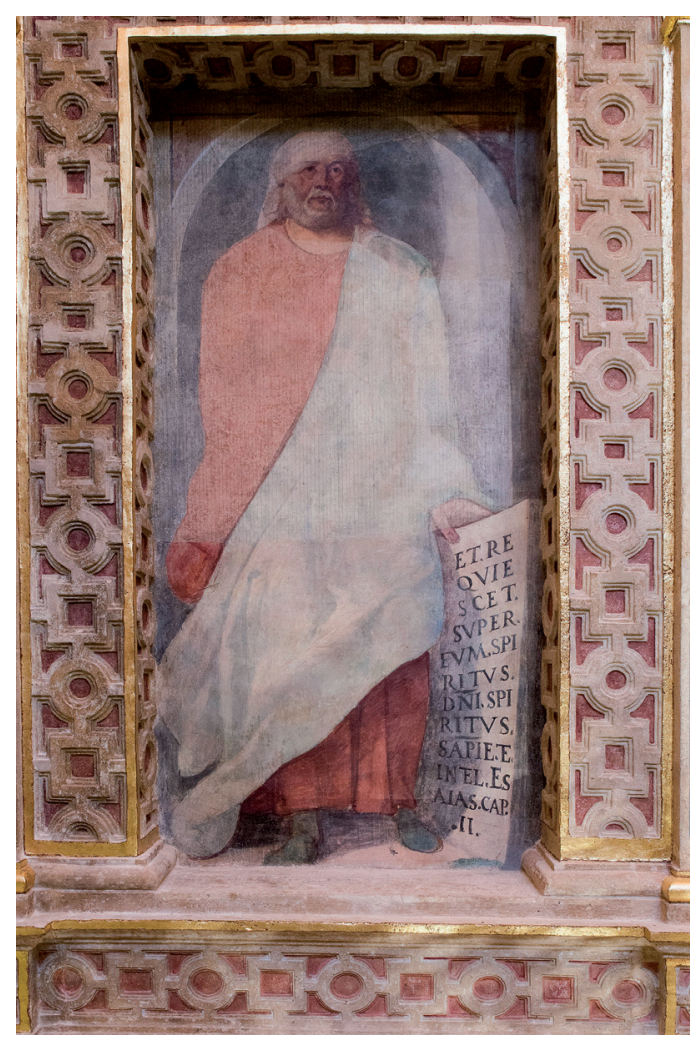

Fig. 5. Córdoba, catedral, capilla del Espíritu Santo, el profeta Isaías.

Llegó a aquella famosa Atenas, donde estuvo siete años en compañía de César Arbasia, como se a dicho. Estudiavan los dos con tan grande ahinco que les amanecía todos los días en este excercicio. Hízose eccelente debuxador i pintor, imitando con ardor increíble las cosas de Micael Ángel i de Rafael de Urbino. Estudió mucho en la historia del juicio, mas en el colorido siguió la hermosa manera de Antonio Corregio $^{16}$.

Llama la atención que la estancia en Roma de Diego de Simancas, entre 1567 y 1576, y la de Pablo de Céspedes, de 1568 (¿?) a 1577, fueron prácticamente coincidentes ${ }^{17}$; de hecho, el obispo de Zamora hospedó a Céspedes en su casa ${ }^{18}$, dato interesante por cuanto ayuda a reconstruir los apoyos que tuvo el racionero en la urbe, comenzando por el clero cordobés, donde existían redes clientelares necesarias para promocionar ${ }^{19}$. Por otra parte, Martínez de la Peña ${ }^{20}$ encuentra registrado a Céspedes en la Academia de San Lucas ${ }^{21}$ de Roma en $1577^{22}$, donde también aparece inscrito Arbasia en $1593^{23}$. No parece aventurado, por tanto, apuntar que don Diego, quien tuvo alojado al racionero, conociera a Cesare Arbasia.

El regreso de Céspedes a Córdoba en 1577 para hacerse cargo de un canonicato ${ }^{24}$, acompañado de Arbasia, encaja con la posible realización, por parte de este último, de los profetas para el segundo nivel de la capilla del Espíritu Santo, ya que, como anticipábamos, en una cartela del primer nivel figura la fecha de 1574. Conviene recordar que don Diego ya había vuelto a la ciudad en 1576 y no sería extraño que pidiera al italiano la realización de estas pinturas, que debió terminar antes de finales de 1579, cuando marchó a Málaga para colaborar en la capilla mayor ${ }^{25}$. Después regresaría a Córdoba, para comenzar en 1583 su intervención en el Sagrario por encargo de quien también formó parte del círculo de Simancas en Roma, el obispo Antonio de Pazos y Figueroa $^{26}$. Con base en esta afirmación, se podría decir que las pinturas descubiertas sirvieron a

${ }^{16}$ Pacheco/Piñero/Reyes (1985): 101.

17 Brown deshizo el error historiográfico de identificar a Pablo de Céspedes como agente en Roma de Carranza (Brown, 1980: 43), apuntando al licenciado Cristóbal de Céspedes (Quílez, 1990: 65).

${ }_{18}$ Pacheco/Piñero/Reyes (1985): 101. Era natural que don Diego acogiera a Céspedes en su casa, pues el albergue de la Academia de San Lucas no entró en funcionamiento hasta 1621 (Martínez, 1968: 295).

19 Soria, 2000: 76-77. Díaz, 2012: 419-424.

${ }^{20}$ Martínez, 1968: 313.

${ }^{21}$ El germen de la academia fue la Compagnia di San Giuseppe in Terrasanta, cuyo presidente a partir de la década de 1570 fue Federico Zúcaro, siendo Céspedes su secretario en 1572 (Moralejo, 2010: 355).

22 Martínez, 1968: 97, 313. Moralejo, 2010, p. 355.

${ }^{23}$ Conti, 1991: 55. Gregorio XIII dio una bula en 1577 para fomentar el estudio de las Artes y propiciar una enseñanza basada en los grandes maestros. Uno de los príncipes de la academia fue Zúcaro, tras su vuelta de España; gran amigo de Céspedes (Moralejo, 2010: 352) y maestro de Arbasia (Ceán, 1800: 42-43). Sobre la academia, véase Martínez, 1968: 293-313.

${ }^{24}$ Baglione, 1642: 30.

${ }^{25}$ Ponz, 1794: 174-175.

${ }^{26}$ Gómez, 1778: 525. 
Arbasia como presentación ante el cabildo y de ensayo para el ciclo de los mártires del Sagrario diseñado por Ambrosio de Morales ${ }^{27}$.

Por otra parte, la técnica al fresco y mixta utilizada en los profetas no era habitual entre los pintores locales de esta época y, sin embargo, fue empleada en la capilla y en el Sagrario con pocos años de diferencia. Recordemos que Arbasia se comprometió a pintar al fresco la capilla del Sagrario y que la alta consideración en que se tenía esta técnica por haber sido empleada magistralmente por Miguel Ángel, admirado por los manieristas, fue en parte inspiradora de la carta que escribió Céspedes a Pacheco sobre la pintura ${ }^{28}$.

Céspedes viajó de nuevo a Italia en 1583 , regresando en $1584^{29}$. Coincide que este mismo año Arbasia, que había ido a Málaga, vuelve a Córdoba para realizar las pinturas del Sagrario ${ }^{30}$. Un año después el italiano arrienda unas casas de Antonio del Corral, tesorero de la catedral ${ }^{31}$. El 2 de agosto de 1585, cuando Arbasia contrata la conclusión de la pintura y dorado de la capilla del Sagrario, continuaba viviendo en la misma collación de San Bartolomé, donde suponemos que tuvo su domicilio hasta 1586, en que abandonó la ciudad para marchar a Málaga y temporalmente a Roma, ciudad a la que regresó definitivamente en $1593^{32}$.

De la estrecha relación entre Arbasia y Céspedes se desprende una influencia recíproca, y es de suponer que la formación del racionero cordobés como humanista ${ }^{33}$, así como su admiración por Miguel Ángel ${ }^{34}$, especialmente en el Juicio Final, además de Rafael y Leonardo, fue compartida con Arbasia, del que se conoce bastante menos ${ }^{35}$.

El asombro fue considerable al comprobar el parecido de las pinturas de la capilla con las del Sagrario realizadas por Arbasia, quien representó nuevamente a David e Isaías flanqueando las puertas del tabernáculo. En primer lugar, es clara la semejanza en cuanto a la composición. Los tres profetas están alojados en hornacinas de medio punto fingidas. Las figuras se asientan sólidamente sobre el suelo, proyectándose sus pies para acusar la perspectiva en dos planos muy cercanos entre sí. Las similitudes aumentan al comprobar la solemnidad con que posan los personajes, mayestáticos los dos más ancianos y soberbio el rey David. No menos importante es el parecido en el tratamiento de la vestimenta. Salvo David, caracterizado como soldado, los otros dos se cubren con amplias túnicas y mantos de abundantes pliegues que acentúan el volumen, especialmente en el caso de Moisés. La relación con las pinturas del Sagrario es evidente en este sentido, pero más aún si comparamos el exuberante colorido aplicado en diferentes tonalidades. Esta preocupación encaja en la idea de Céspedes de que el pintor tenía que ir más allá del modelo natural y del mero retrato, como hacían los renacentistas, para lograr una nueva formulación aunque siguieran inspirándose en los grandes maestros $^{36}$; teoría que quizás compartieran el racionero y Arbasia.

En cuanto a la ubicación de los profetas en un registro por debajo de la bóveda podría evocar la de David y Daniel en los pilares de la capilla Bonfili en la iglesia de la Trinidad de los Montes

27 Pérez, 1991: 57-64.

28 Rubio/Moreno, 1998: 405-411.

29 Pacheco/Piñero/Reyes, 1985: 102. Romero, 1923: 336-347. Martínez Lara, 2012.

30 Conti, 1991: 45-55.

31 Carta de César Arbasia arrendando unas casas propiedad de don Antonio del Corral, 24 de abril de 1585, AHPCO, Protocolos, 12394P, f. 477v.

32 Sobre sus obras en esta etapa final fuera ya de Córdoba, véase Clavijo, 1978: 307-320. Conti, 1991: 55. López, 2007: 198-202.

33 Con una biblioteca de 300 volúmenes aproximadamente y su círculo de amistades, como Arias Montano, Pedro de Valencia, Pacheco y Zuccaro, entre otros (Zueras, 1974: 8-11. Sánchez, 2003: 699-710. Quílez, 1990: 69-73.

34 Palomino, 1715: 1, 153.

35 Palomino, en su nota sobre Cesare Arbasia, apenas ofrece datos novedosos. Lo califica como "gran pintor italiano" y "de la escuela de Leonardo da Vinci" y las fechas que da son erróneas, pues afirma que llegó a España en 1600, donde trabajó en el Sagrario de la catedral de Córdoba. Concluida esta obra, marchó a Italia para estar allí dos años. Afirma que no hay más noticias sobre él, salvo que regresó en 1602 y murió en Italia (Palomino, 1796: 3, 404). Conti, 1991: 49.

36 Quílez, 1990: 84. 


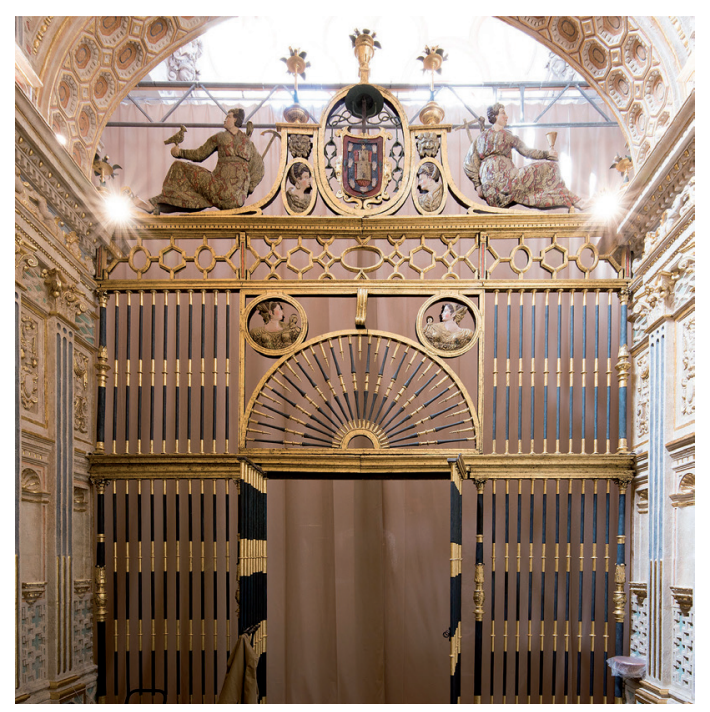

Fig. 6. Fernando de Valencia, Catedral, reja de la capilla del Espíritu Santo, 1573.

en Roma, en la que estuvo Arbasia pintando al fresco con el racionero ${ }^{37}$. Era una forma de destacar la importancia del mensaje de los profetas en estos programas iconográficos.

Por los paralelos con los mártires del Sagrario de Córdoba podrían atribuirse los profetas de la capilla de los Simancas a Arbasia, si bien sería arriesgado hacerlo sin más pruebas, como ha demostrado la cantidad de obras adscritas a Céspedes que posteriormente se han certificado como obras de sus discípulos o simplemente de otros artistas ${ }^{38}$. Pero hoy podemos ir más allá del mero atribucionismo gracias al análisis de las micromuestras de pigmentos con motivo de la restauración ${ }^{39}$, determinantes para corroborar la similitud de la técnica —al fresco y mixta- y de los pigmentos del Sagrario y del Espíritu Santo, por lo cual estaríamos en situación de afirmar que los tres personajes hallados son obra de Cesare Arbasia. Su obra conocida hasta ahora en la catedral de Córdoba eran las pinturas al fresco de la capilla del Sagrario, en las que también parece que intervino Antonio Mohedano ${ }^{40}$.

Dicho esto, sería interesante confirmar que el lienzo de Cristo en el Calvario, con los tres Simancas al pie de la cruz, y el del Bautismo de Cristo, ambos en el retablo de la capilla, fueron obra de Céspedes ${ }^{41}$. En la actualidad hay quienes desechan esta atribución ${ }^{42}$ pero, como señala Urquízar, "resulta difícil de concebir que los hermanos Simancas, que tan relacionados habían estado con el racionero, encargasen la ornamentación de su capilla y sus retratos sin contar con él"

Hay otro aspecto capital en la capilla de los Simancas y es la importante presencia del dorado - con restos de oro fino- y de la policromía en los frisos, reja, pilastras, capiteles, etc., fechables en 1574. Arbasia demostró su experiencia como dorador en la capilla mayor de la catedral de Málaga que comenzó entre finales de 1579 y principios de $1580^{44}$. Más tarde, cuando trabajó en el Sagrario de la sede cordobesa, ya en 1586, se comprometió a pintar al fresco la bóveda, paredes y arcos, y a "dorar y pintar las tres rejas, con sus puertas, y el barandal del comulgatorio" ${ }^{45}$. Dichas rejas eran obra de Fernando de Valencia, el mismo autor de la del Espíritu Santo, que además trabajaba normalmente con Hernán Ruiz. La reja del Sagrario la hizo Valencia en 1571 y en 1573 la

37 Baglione, 1642: 30. Más recientemente, Díaz afirma que los profetas de la capilla Bonfili fueron pintados por Dupré, aunque posiblemente Céspedes los ideara (Díaz, 2006: 22-23).

${ }^{38}$ Urquízar, 20001a: 91. Palencia, 1999: 416.

39 Agradezco esta información a la restauradora Anabel Barrena Herrera.

40 Urquízar, 2001a: 95.

${ }^{41}$ Orti, 1970: 83. Pérez/Moralejo, 2012: 1507. Los da por anónimos, aunque con derivaciones de Céspedes, Raya, 1988: 30

42 Palencia, 1999: 434.

${ }^{43}$ Urquízar, 2001a: 94. Explica la extrañeza que causa el dibujo un tanto irregular del Bautismo con una posible intervención de sus discípulos Juan de Peñalosa y Antonio Mohedano.

${ }^{44}$ Clavijo, 1978: 311.

${ }^{45}$ Escritura de concierto entre el licenciado Juan Pérez de Sevilla, como receptor y mayordomo de la obra y fábrica de la Santa Yglesia, de una parte y de la otra César Arbassia, pintor, italiano, 19 de marzo de 1586, Archivo Histórico Provincial de Córdoba (AHPCO), Protocolos, 16171P, ff. 356-357. 
amplió ${ }^{46}$, y Arbasia la doró y pintó en $1586^{47}$. Se da la circunstancia, por tanto, de que Fernando de Valencia estaba en 1573 modificando la reja del Sagrario y haciendo la del Espíritu Santo ${ }^{48}$. Esto permite apuntar que el propio Arbasia pintara y dorara también la reja de los obispos [fig. 6], así como los elementos decorativos de los paramentos.

En conclusión, la reciente aparición de unas nuevas pinturas al fresco - fechadas entre 1577 y 1579- en la capilla del Espíritu Santo y su atribución al pintor italiano Cesare Arbasia resulta relevante, puesto que, junto con Pablo de Céspedes, introdujo el manierismo en Córdoba contando con la protección del alto clero, en este caso de Diego de Simancas, integrante del selecto círculo de humanistas de la época.

\section{Agradecimientos}

Cabildo catedralicio de Córdoba. Profesor Fernando Moreno Cuadro. Anabel Barrena, restauradora, y equipo técnico. Dr. Esteban Tarradas, del SIADI de la Universidad de Córdoba (fotografías).

\section{BIBLIOGRAFÍA}

Baglione Romano, Giovanni (1642): Le vite de pittori, scultori et architetti. Dal pontificato di Gregorio XIII del 1572. In sino a 'tempi di Papa Urbano Ottavo nel 1642. Roma: Stamperia d'Andrea Fei.

Banda y Vargas, Antonio de la (1999): “Hernán Ruiz y la arquitectura bajoandaluza en tiempos de Felipe II”. En: Vázquez Lesmes, Rafael/Ventura Gracia, Miguel (coords.): Córdoba en tiempos de Felipe II. Córdoba: Cajasur, pp. 389-391.

Brown, Jonathan (1980): Imágenes e ideas en la pintura española del siglo XVII. Madrid: Alianza Editorial.

Campo Muñoz, Juan del (1998): "La familia Peroli y otros italianos en Viso del Marqués (1575-1613)", Boletín del Museo e Instituto Camón Aznar, 73, Zaragoza, pp. 9-33.

Caro Baroja, Julio (1970): El señor inquisidor y otras vidas por oficio. Madrid: Alianza Editorial.

Ceán Bermúdez, Juan Agustín (1800): Diccionario histórico de los más ilustres profesores de las bellas artes, t. 1. Madrid: Imp. Vda. de Ibarra.

Chueca Goitia, Fernando (1953): Arquitectura del siglo XVI. Madrid: Plus Ultra.

Clavijo García, Agustín (1978): "Un pintor manierista en Málaga: el italiano César Arbasia”. En: Actas del I Congreso de Historia de Andalucía: Andalucía Moderna (siglos XVI-XVIII). Córdoba: Monte de Piedad y Caja de Ahorros de Córdoba, t. 1, pp. 307-320.

Conti, Giulia (1991): "Las pinturas del Sagrario de la Catedral de Córdoba". En: Aranda Doncel, Juan (coord.): Homenaje a Dionisio Ortiz Juárez. Córdoba: Imp. San Pablo, pp. 45-58.

Díaz Cayeros, Patricia (2006): Pablo de Céspedes entre Italia y España. Red Anales del Instituto de Investigaciones Estéticas. En: https://elibro.net/es/lc/bibliocordoba/titulos/6684 [17/08/2020]

Díaz Rodríguez, Antonio Jesús (2012): El clero catedralicio en la España Moderna: Los miembros del Cabildo de la Catedral de Córdoba (1475-1808). Murcia: Universidad de Murcia.

Gómez Bravo, Juan (1778): Catálogo de los obispos de Córdoba y breve noticia histórica de su iglesia catedral y obispado, t. 2. Córdoba: Oficina de Juan Rodríguez.

López Torrijos, Rosa (2007): "Sobre pintores italianos en España (Castello, Peroli y el falso Cesare Arbasia en el palacio del Viso". En: In sapientia libertas: escritos en homenaje al profesor Alfonso E. Pérez Sánchez. Madrid/Sevilla: Museo Nacional del Prado/Fundación Focus-Abengoa, pp.198-202.

Lynn, Kimberly (2013): Between Court and Confessional: The Politics of Spanish Inquisitors, Cambridge: Cambridge University Press.

Martínez Lara, Pedro Manuel (2012): Pablo de Céspedes. Estudio de los procesos de producción y asimilación entre Italia y España, entre el Renacimiento y el Barroco, Tesis doctoral. Sevilla: Universidad de Sevilla.

Martínez Lara, Pedro Manuel (2018): "Pablo de Céspedes y el aprendizaje de la pintura entre Roma, Córdoba y Sevilla". En: Alonso, Begoña/Villaseñor, Fernando (eds.): XXI Congreso del CEHA Santander 2016. La formación artística: creadores, historiadores, espectadores. Santander: Universidad de Cantabria, pp. 201-213.

${ }^{46}$ Contrato con Fernando de Valencia, AHPCO, Torre y del Cerro, José de la. Caja "Artistas varios. Monumentos", ficha 1958. En cuanto a las condiciones de la pintura y dorado de esta reja, véase Ortiz Juárez, 1970: 131.

${ }^{47}$ Escritura entre Juan Pérez de Sevilla y César Arbasia, 19 de marzo de 1586, AHPCO, Protocolos, legajo 16171P, ff. $356 \mathrm{r}-357 \mathrm{r}$

${ }^{48}$ Contrato con Fernando de Valencia para la realización de la reja de la capilla de los Simancas, 26 de agosto de 1573, AHPCO, Protocolos, legajo 9050P, f. 1.060r. 
Martínez de la Peña y González, Domingo (1968): “Artistas españoles en la Academia de San Lucas (documentos de los siglos XVI y XVII)”. En: Archivo Español de Arte, XLI, 164, Madrid, pp. 293-313.

Menor Borrego, Bartolomé (2000): "Poesía y teología en las pinturas de César Arbassia en la capilla del Sagrario de Córdoba". En: Boletín de la Real Academia de Córdoba, 139, Córdoba, pp. 141-150.

Moralejo Ortega, Macarena (2010): “Amigos e interlocutores de Pablo de Céspedes en Roma: nuevos datos”. En: Anuario de Historia de la Iglesia Andaluza, 3, Sevilla, pp. 227-240.

Moralejo Ortega, Macarena (2012): "El obispo Diego de Simancas y su papel como virrey de Nápoles". En: Libros de la Corte, 4, Madrid, pp. 141-153.

Morales Martínez, Alfredo J. (1996): Hernán Ruiz “El Joven”, Madrid: Akal.

Moreno Cuadro, Fernando (2018): "El tabernáculo de Guillermo de Orta para la capilla del Sagrario de la catedral de Córdoba”. En: Anuario de Historia de la Iglesia, 27, Pamplona, pp. 341-342.

Nieto Cumplido, Manuel (1991): “Aportación documental a la obra de Hernán Ruiz I en la Mezquita-Catedral de Córdoba (1513-1547)". En: Aranda Doncel, Juan (coord.): Homenaje a Dionisio Ortiz Juárez. Córdoba: Ayuntamiento de Córdoba, pp. 209-245.

Orti Belmonte, Vicente (1970): La catedral-antigua mezquita y santuarios cordobeses. Córdoba: Monte de Piedad y Caja de Ahorros.

Pacheco, Francisco / Piñero Ramírez, Pedro / Reyes Cano, Rogelio (1985): Libro de descripción de verdaderos retratos de ilustres y memorables varones. Sevilla: Diputación Provincial.

Palencia Cerezo, José María (1999): “La pintura cordobesa en tiempos de Felipe II”. En: Vázquez Lesmes, Rafael / Ventura Gracia, Miguel (coords.): Córdoba en tiempos de Felipe II. Córdoba: Cajasur, pp. 415-436.

Palomino de Castro y Velasco, Antonio (1715): El museo pictórico y escala óptica. Madrid: Lucas Antonio de Bedmar.

Palomino de Castro y Velasco, Antonio (1796): El parnaso español pintoresco laureado. Madrid: Imprenta de Sancha.

Pérez Lozano, Manuel (1991): "Los programas iconográficos de la capilla del Sagrario de la catedral de Córdoba". En: Cuadernos de Arte e Iconografia, 4, 8, Madrid, pp. 57-64.

Pérez Lozano, Manuel / Moralejo Ortega, Macarena (2012): "Don Diego de Simancas y la fundación de la capilla familiar en la Catedral-Mezquita de Córdoba". En: Barral Rivadulla, María Dolores / Fernández Castiñeiras, Enrique / Fernández Rodríguez, Begoña / Monterroso Montero, Juan Manuel (eds.): Mirando a Clío. El arte español espejo de su historia. Santiago de Compostela: Universidad de Santiago de Compostela, pp. 1501-1513.

Ponz, Antonio (1794): Viage de España, ó Cartas, en que se da noticia de las cosas mas apreciables, y dignas de saberse que hay en ella, t. 18. Madrid: D. Joachin Ibarra.

Quílez Corella, Miquel (1990): "La cultura artística de Pablo de Céspedes". En: Boletín del Museo e Instituto Camón Aznar, XXXIX, Zaragoza, pp. 65-85.

Raya Raya, Ma Ángeles (1988): Catálogo de las pinturas de la catedral de Córdoba. Córdoba: Monte de Piedad y Caja de Ahorros.

Rodríguez, Alonso (1760): Exercicio de perfección y virtudes christianas. Barcelona: Imp. María Ángela Martí Viuda.

Romero de Torres, Enrique (1923): "Expediente canónico incoado en 1589 contra el célebre pintor cordobés y racionero Pablo de Céspedes y noticia de algunos de sus cuadros", Boletín de la Real Academia de la Historia, LXXXVI, Madrid, pp. 336-347.

Rubio Lapaz, Jesús / Moreno Cuadro, Fernando (1998): Escritos de Pablo de Céspedes. Edición crítica. Córdoba: Diputación de Córdoba.

Sánchez López, Juan Antonio (2003): “Cesare Arbassia, un pintor italiano para los círculos humanistas hispanos del siglo XVI”. En: Villar García, María Begoña/ Pezzi Cristóbal, Pilar (dirs.): I Coloquio Internacional "Los extranjeros en la España moderna”. Málaga: Ministerio de Ciencia e Innovación, t. 2, pp. 699-710.

Sigüenza, José de / García Aguilar, Ignacio / Fernández López, Sergio / Palomino Tizado, Natalia (2014): La historia del Rey de los Reyes y Señor de los Señores. Huelva: Universidad de Huelva.

Simancas, Diego de (1905): La vida y cosas notables del Señor Obispo de Zamora D. Diego de Simancas..., escrita de su mano. En: Serrano y Sanz, Manuel (ed.): Autobiografias y memorias. Madrid: Librería Editorial Bailly-Baillière e hijos, Nueva Biblioteca de Autores Españoles, 2, pp. 151-210.

Soria Mesa, Enrique (2000): El cambio inmóvil. Transformaciones y permanencias en una élite de poder. (Córdoba, ss. XVI-XIX). Córdoba: Ayuntamiento de Córdoba.

Urquízar Herrera, Antonio (2001a): El Renacimiento en la periferia. La recepción de los modelos italianos en la experiencia pictórica del Quinientos cordobés. Córdoba: Universidad de Córdoba.

Urquízar Herrera, Antonio (2001b): Historiadores y pintores. Historia de la historiografía de la pintura del siglo XVI en Córdoba. Córdoba: Diputación Provincial.

Villar Movellán, Alberto (1990): "Arquitectura en Andalucía occidental”. En: Pareja López, Enrique (dir.): Historia el Arte en Andalucía, t. 4. El arte del Renacimiento. Urbanismo y Arquitectura. Sevilla: Gever, pp. 282-399.

Zueras Torrens, Francisco (1974): “Los pintores-escritores con Céspedes como arquetipo". En: Boletín de la Real Academia de Córdoba, 94, Córdoba, pp. 9-23.

Fecha de recepción: 07-XI-2020

Fecha de aceptación: 03-II-2021 